\title{
GRUPO DE ESTUDOS: APRENDIZAGEM ATIVA DURANTE A PANDEMIA DA COVID-19
}

\section{Vera Maria Medina Simonetti ${ }^{1}$}

RESUMO: Transformações significativas estão sendo realizadas nos contextos socioeconômicos no mundo devido à pandemia iniciada no final de 2019. Nunca na história da educação brasileira ocorreram tantos momentos difíceis e impactantes. Mediante esse contexto histórico ímpar, propomos esforços que reunissem a orientação do CNE com a da SEEDUCRJ, a fim de implementar a atividade grupo de estudos com jovens do ensino médio público, sob a supervisão de um adulto. Este estudo se baseou na abordagem qualitativa descritiva e utilizou o paradigma metodológico. Os respondentes apontaram que a atividade grupo de estudos atuou como reforço da aprendizagem, como motivador mediante contato com os colegas e auxiliou nas dúvidas e melhorou a compreensão dos conteúdos. A sensação de sobrecarga com os estudos e a situação da pandemia interferiram na disposição do grupo para participar dos encontros. Os saberes intercambiados no grupo possibilitaram o desenvolvimento crítico e reflexivo dos conteúdos e a elaboração de uma lista de elementos essenciais para atividade grupo de estudos. Esperamos ter contribuído para a práxis de estratégias ativas que propicia visão crítica no processo de ensino-aprendizagem.

Palavras-chave: grupo de estudos. estratégias ativas. processo de ensino-aprendizagem. pandemia.

ABSTRACT: Significant changes are taking place in socioeconomic contexts around the world due to the pandemic that started in late 2019. Never in the history of Brazilian education there have been so many difficult and impacting moments. In the face of it, we proposed efforts that would combine the guidance of the CNE with that of SEEDUC-RJ, in order to implement the study group activity with public high school youths, under the supervision of an adult. This study was based on the qualitative descriptive approach and used the methodological paradigm. The respondents pointed out that the study group activity acted as a reinforcement of learning, as a motivator upon contact with colleagues and helped with doubts and improved understanding of the contents. The feeling of overload with studies and the pandemic situation

I Ph.D. em Educação Claremont Graduate School (E.U.A). Pesquisadora autônoma. E- mail: edupsi@terra.com.br. 
interfered with the group's willingness to participate in the meetings. The knowledge exchanged in the group enabled the critical and reflective development of the contents and to present a list of essentials' elements for study group activity. We hope to have contributed to the practice of active strategies that provide a critical view in the teaching-learning process.

Key-words: study group. active strategies. teaching-learning process. pandemic.

\section{INTRODUÇÃO}

Nunca na história da educação brasileira ocorreram tantos momentos difíceis e impactantes como no contexto atual da pandemia da covid-I9. Escolas fechadas às pressas, gestores, professores, alunos e seus respectivos familiares perplexos com a duração da quarentena e do distanciamento social. Em paralelo, a real necessidade de se manter o ensino contínuo, gerou movimentos de acertos e erros do início ao fim de 2020.

A partir de novembro desse ano, o crescimento vertiginoso das estatísticas de contaminados e de óbitos caracterizou o surgimento da segunda onda da pandemia em todo território nacional. Momentos mais duros foram registrados no primeiro trimestre de 202I. Assim sendo, o sistema híbrido do ensino na educação básica foi adotado em larga escala, oferecendo o ensino presencial e o remoto, estando o primeiro condicionado a classificação de risco de contaminação.

Um cenário educacional mais alentador para 2021 foi atropelado por impasses políticos no campo da saúde do nosso país, principalmente em se tratando dos grupos prioritários para imunização contra a covid-ı. Os profissionais do sistema educacional não foram incluídos nestes grupos e as escolas continuaram com suas atividades presenciais canceladas no início do ano letivo. Desafios voltados para o ensino remoto ficaram mais evidentes neste ano. Professores e alunos não possuíam acesso às aulas em plataformas digitais, por falta de qualificação, de equipamentos tecnológicos e/ou conectividades como relataram Lima e Mota Neto (2021).

Outrora o ensino a distância na educação básica no Brasil atendia aos cursos profissionalizantes, à complementação da aprendizagem ou para situações emergenciais, segundo a Lei das Diretrizes e Bases da Educação (BRASIL, 1996). O cenário pandêmico atual levou ao enquadramento da educação básica como momento emergencial. Desta forma, o Conselho Nacional de Educação (CNE) aprovou, há um ano, as diretrizes para as instituições educacionais considerando o ensino a distancia durante a pandemia do coronavirus (BRASIL, 2020). No que tange a educação básica, o CNE recomendou que 
A supervisão de um adulto para realização de atividades pode ser feita por meio de orientações e acompanhamentos com o apoio de planejamentos, metas, horários de estudo presencial ou on-line, já que nesta etapa há mais autonomia por parte dos estudantes. Neste caso, a orientação é que as atividades pedagógicas não presenciais tenham mais espaço. Entre as sugestões de atividades, está a distribuição de vídeos educativos (BRASIL, 2020, s/p).

Em se tratando do ensino público na região sudeste, principalmente das escolas estaduais, diretrizes pedagógicas apoiadas na tecnologia do ensino online foram determinantes para o resgate do ensino contínuo. A Secretaria de Educação do Rio de Janeiro (SEEDUC-RJ) apresentou o Plano de Estudo para Alunos 2021, iniciado em 03 de março do ano corrente através da Plataforma Google ${ }^{\circledast}$. No final deste Plano uma lista de dicas para ter sucesso no estudo remoto foi apresentada, indo de sugestões motivacionais ao estudo da gestão de planejamento e de tempo (RIO DE JANEIRO, 2021a, p. 5).

Refletimos sobre a importância da recomendação do CNE (BRASIL, 2020) e da dica motivacional de grupo de estudos na rotina do aprendizado remoto da SEEDUC-RJ (RIO DE JANEIRO, 202Ia); uma estratégia pedagógica ativa e interessante para esse momento de distanciamento social. Diversos estudos investigaram a influência de estratégias ativas no processo de ensino-aprendizagem na educação básica e no ensino superior. Os resultados apontaram para os benefícios destas estratégias (OLIVEIRA; SIQUEIRA; ROMAO, 2020; ANTICH; FORSTER, 2012; SILVA, 20II; SIMONETTI, 1996).

Temos um interesse intrínseco nesse assunto específico sobre processo de ensinoaprendizagem com a aplicação de estratégias ativas. Assim, acatando a recomendação do CNE (BRASIL, 2020) de que as atividades escolares no ensino médio poderiam ser acompanhadas e orientadas por um adulto nesses tempos essenciais de pandemia e a recomendação da Secretaria de Educação do Rio de Janeiro (RIO DE JANEIRO, 202ia) de se estudar também através da atividade grupo de estudos, vislumbramos a possibilidade de compartilhar nossos conhecimentos acadêmicos com alunos da educação básica. Especificamente, aqueles matriculados na $3^{2}$ série do ensino médio regular, em uma escola estadual, provenientes de contatos pessoais e que tivessem interesse em participar de uma pesquisa.

Durante nosso contato, observamos que a compreensão sobre grupo de estudos perpassava o conhecimento e experiência daqueles alunos e o quanto seria relevante contribuir na definição, planejamento e aplicação desta atividade. Sendo assim, surgiu o interesse de dividir nossa experiência profissional de forma voluntária, num âmbito maior, unindo conhecimento teórico à aplicação prática através da lente científica. Por acreditarmos que o conhecimento é construído socialmente, este estudo pretende estimular insights nos participantes e em outras pessoas a 
refletir e reconstruir suas práticas, levando à epistemologia do particular, como salienta Dezin e Lincoln (1994).

A investigação da implementação do grupo de estudos, numa realidade histórica sem precedentes, comportou uma metodologia da abordagem qualitativa, tendo o conteúdo histórico descrito por experiência autentica de cada participante. O paradigma metodológico norteou esta questão através de contato direto e constante da pesquisadora com os jovens participantes, descrevendo os procedimentos e os passos necessários à práxis. O método de coleta de dados foi hermenêutico, buscando a compreensão através da interpretação do contexto.

Para isso, o referencial teórico teve como base o Plano de Estudo para Alunos 202i que norteou o planejamento das etapas do grupo de estudos, indo da elaboração de um Calendário de Estudos até a distribuição do conteúdo curricular a ser estudado (RIO DE JANEIRO, 202ra). No tocante as características do grupo de estudos, Slaymaker (2020) contribuiu com os aspectos importantes para a formação do grupo e Schoenherr (2006) no tocante a eficácia do mesmo. A metodologia de pesquisa seguiu os parâmetros qualitativos e metodológicos baseados em Dezin e Lincoln (1994) e Demo (199I).

\section{Plano pedagógico do estado do Rio de Janeiro}

O Plano Pedagógico foi desenvolvido por professores da rede estadual de ensino do Rio de Janeiro e foi apresentado aos alunos em um encontro presencial nas unidades escolares, na primeira quinzena de março de 202r. Para as $2^{-}$e $3^{\text {a }}$ séries do ensino médio regular, foi informado que haveria uma revisão do conteúdo do ano anterior, cursado em 2020, planejada em dois momentos: $\mathrm{I}^{\circ}$ e $2^{\circ}$ bimestres realizados em março e o $3^{\circ}$ e $4^{\circ}$ bimestre realizados em abril (RIO DE JANEIRO, 202ia). Os conteúdos curriculares eram referentes a cada matéria do ano que o aluno cursou em 2020 e foram sendo introduzidos de forma escalonada. As ações avaliativas foram bimestrais e compostas por participação nas aulas onlime e nas trocas de mensagens com os professores, por assiduidade e realização de atividades propostas e entregues dentro de prazo estipulado previamente.

Todo conteúdo curricular da escola foi acessado gratuitamente pelo aplicativo educacional Applique-se ${ }^{\circledast}$. Este aplicativo ofertou múltiplas linguagens como recursos pedagógicos de acesso direto e rápido aos conteúdos curriculares. As matérias do ensino médio foram disponibilizadas em ordem alfabética e organizadas através de Orientações de Estudo (OEs), videoaulas e podcasts. Ainda, o ambiente virtual de sala de aula do Google Classroom ${ }^{\circledR}$ permitiu compartilhamento de conteúdos curriculares e interação com os professores. Dessa forma, cada matéria foi composta por uma OE, uma videoaula (dependendo da matéria) e entre cinco e quatro podcasts para cada bimestre. 
As OEs possuíam material escrito, tipo apostila, e alguns links para acesso a vídeos que apresentavam o conteúdo programático de cada matéria e sua respectiva atividade avaliativa ao final. Cada OE era composta por cinco aulas e uma de conclusão e cada aula possuía um podcast respectivo e, às vezes, uma videoaula. As videoaulas eram recursos audiovisuais e os podcasts eram recursos de áudio. As videoaulas tinham uma duração média de 15 minutos cada, com intérpretes de libras, e os podcasts duração diversas.

Além dos recursos pedagógicos para acessar o conteúdo programado, através do aplicativo educacional Applique-se ${ }^{\circledR}$, os professores também podiam incluir informações adicionais de leituras, de exercícios, links para consultas e reuniões ao vivo pelo tutorial Google Meet $^{\circledR}$.

\section{Atividade grupo de estudos}

O estudo individual é o primeiro contato do aluno com o material do conteúdo curricular; a leitura e a prática de exercícios incluídos neste material estimulam a perspectiva pessoal, mas carece de irrigação intelectual. As estratégias pedagógicas ativas preenchem essa necessidade de estimulação cognitiva, onde se observa que cada aluno desenvolve seus próprios meios de estudo e através do intercâmbio de conhecimento. As lacunas existentes em determinados temas podem ser preenchidas com a explicação de um colega.

Schoenherr (2006) comentou que a eficácia do aprendizado proporcionado por grupo de estudos é maior do que o individual, devido ao contexto dinâmico onde se desenvolve. $\mathrm{O}$ aprendizado individual sofre influência de anotar o que o professor ensina, juntamente com os elementos dispersivos encontrados em sala de aula ou fora dela, redundando em passividade e desinteresse por parte dos alunos.

Em contrapartida, a atividade grupo de estudos permite que os alunos possam acelerar o aprendizado lendo, refletindo e exercitando em conjunto sobre o tema da matéria. Além deste benefício, a atividade elimina a procrastinação, já que o estudo com outros colegas permite que a experiência seja mais motivante e menos entediante. $O$ fato de ter um planejamento com data e conteúdo a ser preparado, incentiva o estudo prévio, o foco no assunto estipulado e o compromisso com o grupo.

A esse respeito, podemos citar o Pforzheimer Learning and Teaching Center (PLTC) [Centro de Ensino e Aprendizagem Pforzcheimer], localizado em Massachussets, nos Estados Unidos da América, que auxilia professores com diferentes técnicas de ensino e inovações pedagógicas e auxilia alunos a maximizarem suas oportunidades educacionais e seus potenciais acadêmicos. Os responsáveis pelo PLTC afirmaram que com o grupo de estudos, os alunos desenvolvem habilidades para discutirem temas, para colocarem suas ideias, para perceber lacunas no seu aprendizado, para aprender com o outro e para socializar com seus pares. A 
construção de mapeamento de conceitos e a revisão do conteúdo para testes e provas se beneficiam da troca coletiva de conhecimento. Outra questão mencionada é o intervalo entre estudos, que pode atender alguma necessidade pessoal como ida ao banheiro ou para socialização, que também se faz possível ao final de cada atividade (SCHOTKA, 2020, tradução nossa).

O vínculo de amizade entre os participantes não é condição sine qua non para a formação do grupo. $O$ interesse em estudar é o mais importante, juntamente com disponibilidade e dedicação para os estudos. Os jovens devem manter respeito e mente aberta pelas colocações dos colegas. Um membro do grupo deve fazer papel de líder para transmitir a todos as regras e os objetivos a serem seguidos e ao que se é planejado inicialmente. Durante o estudo o líder é aquele que desestimula as conversas paralelas em prol de promover a partilha de saberes. $\mathrm{O}$ membro, que tiver mais segurança num determinado tema, lidera a explicação.

Slaymaker (2020, tradução nossa) apresentou os ${ }_{4} \mathrm{Ws}$ (Who, When, Where e What) [quem, quando, onde e o quê] para se construir um grupo de estudos eficaz. Ela descreveu que a escolha dos 3-6 membros do grupo (quem) precisa levar em consideração a intenção da participação: para estudar e não para lazer. Na decisão do quando e onde se encontrar, é importante um dia/horário/local constante e de comum acordo, variações são possíveis quando aplicáveis para a situação. No o quê estudar, o conteúdo programático deve ser distribuído levando em consideração o tempo e a frequência dos encontros. Por último, Slaymaker destacou que dois fatores para o sucesso do grupo são desenvolver uma agenda e distribuir o conteúdo para cada encontro estipulado. Esse planejamento permite que cada participante possa se preparar com antecedência.

\section{Metodologia da pesquisa}

Este estudo se baseou na abordagem qualitativa descritiva, em busca do como se dá o processo e utilizou o paradigma metodológico por investigar os caminhos da aplicabilidade de uma atividade de aprendizagem (DEZIN; LINCOLN, 1994; DEMO, 199I). A implementação foi descrita do início ao fim apresentando o motivo pelo qual foi proposta, as etapas de desenvolvimento, os participantes envolvidos e os resultados alcançados, durante o período de março a junho de 2021, durante a pandemia da covid-r9.

O objetivo geral deste estudo foi implementar a atividade grupo de estudos no processo de aprendizagem de jovens da $3^{\mathrm{a}}$ série do ensino médio regular, de um colégio estadual. Dentro deste contexto, os objetivos específicos foram:

I) identificar aspectos relevantes para a implementação da atividade grupo de estudos no processo de aprendizagem, através da prática de jovens da $3^{\underline{a}}$ série do ensino médio regular, de um colégio estadual; 
2) apresentar os elementos essenciais para o planejamento da atividade grupo de estudos, através da prática de jovens da $3^{\underline{a}}$ série do ensino médio regular, de um colégio estadual.

O estudo foi interpretado por meio dos métodos de observação, entrevista em grupo face a face e questionário individual aplicados nos participantes para registrar suas impressões sobre a atividade grupo de estudos. Os fatos percebidos de forma direta foram registrados pelo método observação através das anotações de campo da pesquisadora, durante e após cada encontro com os jovens participantes. As entrevistas foram realizadas pessoalmente e em grupo, denominadas entrevista de grupo face a face (FONTANA; FREY, 1994, tradução nossa). As questões eram semi-estruturadas, iniciando com temas abertos e deixando espaços para comentários. Durante as entrevistas não fizemos registros sobre os relatos, a fim de evitar timidez e desconforto. Logo após, os principais pontos colocados foram anotados, juntamente com as nossas impressões dos fatos. O questionário era estruturado, com 14 itens em forma de afirmativas para os respondentes selecionarem entre as três opções de respostas (concordo, às vezes e discordo), a que melhor refletia sua opinião individual. Estes métodos foram selecionados por proporcionarem direcionamento e por captar a perspectiva dos participantes, de forma individual e coletiva.

A apresentação final das informações coletadas foi consolidada no panorama geral, onde registramos os aspectos relevantes da implementação da atividade de grupo de estudos, através de categorias provenientes da coleta dos três métodos aplicados (observação, entrevista em grupo face a face e questionário), e os elementos essenciais para o planejamento da atividade.

\section{Implementação do grupo de estudos}

Desde o primeiro contato para a seleção dos jovens participantes, relatamos que essa atividade de aprendizagem estava sendo formado derivado da recomendação do CNE (BRASIL, 2020), sobre a supervisão de um adulto para orientações e acompanhamento das atividades presenciais ou online, e da SEEDUC-RJ sobre a dica motivacional do Plano de Estudos para Alunos 202I (RIO DE JANEIRO, 202Ia). Em seguida explicamos que estaríamos participando do desenvolvimento de uma pesquisa para se registrar a correta implementação do grupo de estudos e contribuir com os registros derivados de sua prática. Todos receberam esta informação com entusiasmo e concordaram em participar do estudo.

A apresentação da prática metodológica a seguir incluiu as etapas para o planejamento dos estudos e dos encontros, como também as informações provenientes dos métodos de coleta, seguida da contextualização sobre a parada emergencial da atividade.

\section{I Planejamento do grupo de estudos}

A organização da formação do grupo e dos encontros seguiu os $4 \mathrm{Ws}$ apresentados por Slaymaker (2020) que são quem, quando, onde e o quê. Notamos que no nosso primeiro encontro, 
os jovens pareciam tímidos de início, mas foram ficando mais a vontade com a construção das normas de participação de cada membro no grupo, a saber:

I. A pesquisadora ficaria responsável pelo planejamento e organização dos conteúdos curriculares através de um Calendário de Estudos;

2. Membros do grupo teriam que querer estudar e desejar bom resultado no Exame Nacional do Ensino Médio (ENEM);

3. Cada membro deveria comparecer com leituras e exercícios feitos;

4. Cada membro deveria trazer suas próprias anotações;

5. O/A líder seria responsável por definir, junto com o grupo, o local de encontro antecipadamente;

6. O/A líder seria o responsável pela comunicação dos conteúdos a serem estudados e por manter o foco de todos no estudo;

7. Todos os membros deveriam manter a disciplina e o foco no conteúdo indicado antecipadamente pelo líder;

8. Cada encontro deveria ter 60-90 minutos de duração, sendo is minutos para intervalo entre as matérias;

9. Cada membro deveria ser assíduo e pontual aos encontros pré-determinados;

Io. Todos os participantes teriam que seguir os protocolos sanitários de prevenção à covid-ı9.

5.I.I Formação do grupo

Quem

A princípio os participantes totalizavam nove jovens oficialmente matriculados no ano letivo de 2021, na $3^{\text {a }}$ série do ensino médio regular, de um mesmo colégio estadual, situado no município de Maricá, localizado na Região Metropolitana da cidade do Rio de Janeiro. Desde o primeiro contato para formação do grupo através do aplicativo Whatsapp ${ }^{\circledR}$ o número de interessados foi diminuindo até que se fechou o grupo com cinco membros: quatro jovens e a pesquisadora. Aqueles que saíram tiveram questões pessoais que os impediriam de frequentar os encontros.

Os jovens participantes possuíam equipamentos digitais móveis e não tinham problema de conectividade. A faixa etária deles era de 16 a 18 anos, dois do sexo feminino e dois do masculino. Após o primeiro encontro, o participante de 18 anos saiu do grupo por questões de cunho íntimo, quando continuamos com três jovens até o final da atividade (dois do sexo feminino, um do sexo masculino, sendo os três entre i6 e i7 anos).

A pesquisadora ficou responsável por elaborar, supervisionar e sanar as dúvidas referentes à aplicabilidade da atividade grupo de estudos durante o desenvolvimento do trabalho. Usou de sua autoridade para apresentar de forma dialógica e responsável, mas sem abrir mão 
do rigor criativo, a aplicação desta atividade. Estimulou e coletou diretamente os dados; direcionou o planejamento dos conteúdos curriculares; atuou como sujeito da produção do saber, criando possibilidades para a construção do conhecimento. Iniciado os trabalhos, a pesquisadora foi se retirando como participante diretiva, a fim de abrir espaço para iniciativas e responsabilidades do grupo ao ato de estudar coletivamente.

5.I.2 Planejamento dos encontros

\section{Onde}

O local para os encontros foi alternado entre duas residências dos participantes, sempre em área externa onde mesas e cadeiras foram higienizadas previamente. Os outros protocolos sanitários contra o coronavirus foram higienização das mãos, uso de máscara facial, distanciamento social e uso individual de equipamentos e materiais.

\section{Quando}

A prática da atividade grupo de estudos pode ser na modalidade presencial ou remota. Como os jovens participantes desse estudo eram provenientes de famílias que seguiam à risca os protocolos sanitários contra o coronavirus, decidimos que os encontros seriam presenciais, sempre aos sábados, preferencialmente no turno vespertino.

5.I.3 Planejamento do conteúdo a ser estudado

\section{O quê}

O estudo iniciou junto com o calendário escolar oficial em 03 de março de 2021. Os quatro participantes (três jovens mais a pesquisadora) discutiram sobre seus hábitos individuais de estudo e como incluiriam essa nova modalidade em suas rotinas. Os jovens optaram em inserir a revisão do conteúdo da $2^{-}$série em suas rotinas de estudo individuais, mantendo os encontros do grupo de estudos voltados para o conteúdo da $3^{\text {a }}$ série, haja vista que dois dos três jovens atuaram ativamente no aprendizado do ensino remoto da $2^{\text {a }}$ série em 2020 e o outro de forma parcial. Assim, seriam acrescentados no Calendário de Estudos do grupo, dois encontros para revisão do conteúdo curricular da $2^{\underline{a}}$ série ao final de cada bimestre, antecedendo as respectivas avaliações bimestrais determinadas pela unidade escolar.

\subsection{Planejamento do Calendário de Estudos}

O conteúdo curricular foi disponibilizado segundo as Orientações de Estudo (OEs), como indicado no Plano de Estudos para Alunos 202I (RIO DE JANEIRO, 202ra). Por conseguinte, o $\mathrm{I}^{\mathrm{o}}$ bimestre foi dividido em quatro encontros, aos sábados, e as matérias da $3^{\underline{a}}$ série ficaram assim distribuídas: 
$I^{o}$ encontro - o6 de março - As matérias foram biologia, educação física e geografia para estudarem na OE a Introdução + aulas i e 2. Videoaulas + Podcasts i e 2. Na matéria de Inglês foi a OE aula I + videoaula + Podcast I.

$2^{-}$encontro - 13 de março - I) As matérias foram biologia, educação física e geografia para estudarem a OE Aulas 3 e 4. Inglês aulas 2, 3 e 4. Videoaulas + Podcasts 3 e 4.

2) As matérias foram história, física, filosofia, português, química, matemática e sociologia para estudarem a OE Introdução + aulas I e 2. Videoaulas + Podcasts i e 2.

$3^{0}$ encontro - 20 de março - I) As matérias foram história, física, filosofia, português, química, matemática e sociologia para estudarem na $\mathrm{OE}$ aulas 3 e 4 . Videoaulas e Podcasts 3 e 4.

2) Todas as matérias para estudarem na OE aula 5. Exercícios. Videoaulas e Podcast 5.

$4^{\underline{o}}$ encontro - 27 de março - Revisão do $\mathrm{I}^{\circ}$ bimestre para a $\mathrm{I}^{\mathrm{a}}$ quinzena de abril quando a unidade escolar agendou avaliação da aprendizagem para o conteúdo programático da $2^{\underline{a}}$ série.

\subsection{Registro da coleta de informações}

A aplicação dos métodos seguiu o local e datas dos encontros do grupo conforme Calendário de Estudos. Aplicamos as entrevistas e o questionário de forma empática, sem interferir ou influenciar a resposta de cada participante, como deve ser segundo Fontana e Frey (1994, tradução nossa). Todos os jovens participantes responderam as mesmas questões e na mesma ordem. Os registros incluíram as anotações de campo originadas do método observação, os relatos das entrevistas de grupo face a face e as respostas do questionário como veremos a seguir. 5.3.I Observação

Os encontros para estudo acompanharam a distribuição do conteúdo programático apresentado no Calendário de Estudos do grupo e entregue aos jovens participantes, que decidiram mantê-lo sem necessidade de alteração. $O$ início de cada encontro era sempre sobre conversas amistosas, voltadas para o cotidiano de cada um. Posteriormente iniciavam os estudos com atenção e participação de todos.

Todos compareceram aos encontros com os conteúdos lidos e anotados. Observamos que o aplicativo educacional Applique-se ${ }^{\circledast}$ era consultado durante o estudo, quando sentiam necessidade de aprofundamento. A participação ativa de todos os jovens permitiu que eles pudessem contrastar suas ideias e ampliar seus conhecimentos. 
Concomitante ao estudo do grupo referente ao conteúdo curricular da $3^{\underline{a}}$ série, os jovens conseguiram entregar as tarefas referentes à 2a série assiduamente e estavam satisfeitos com as pontuações recebidas pelos professores. Destacamos a fala de um dos jovens participantes: "estou me sentindo mais motivada para estudar. Estava difícil ter disciplina antes do grupo de estudos ...”.

5.3.IEntrevista em grupo

Estivemos presente durante as entrevistas em grupo, modalidade face a face, quando aplicamos duas questões no primeiro e segundo encontros. Abaixo apresentamos um resumo das colocações dos participantes seguindo a ordem das questões adicionadas aos comentários:

I. Como vocês estão se sentindo reunidos para o início do grupo de estudos?

A maioria respondeu que se sentia bem e um jovem colocou que estava preocupado em não dar conta porque estava com muita dificuldade para estudar desde a suspensão das aulas presenciais. Os outros participantes comentaram que eles iriam ajudá-lo.

2. Poderiam comentar sobre as orientações do Calendário de Estudos para os encontros?

Todos sinalizaram que fizeram as tarefas e que ficaram motivados com o conteúdo inicial da $3^{\underline{a}}$ série, apesar de terem achado fácil. Concluíram que deveria ser revisão da $2^{\mathfrak{a}}$ série.

3. Como foi a ambientação de vocês com o aplicativo educacional?

Os jovens comentaram que estava diferente do aplicativo Classroom ${ }^{\circledR}$ do ano passado e que tiveram dificuldades para encontrar o material escrito até receberem o auxílio do líder do grupo de estudos por Whatsapp ${ }^{\circledR}$. A pesquisadora acessou o aplicativo para orientar o líder nesta dúvida específica.

4. Ao final das questões, o momento foi livre para colocações.

Os jovens reclamaram que se sentiam ignorados pela gestão escolar e que não tinham a quem recorrer de lá. O número do telefone disponibilizado não atendia as ligações. Todos colocaram que não concordavam com a obrigatoriedade de todos os alunos da $3^{\underline{a}}$ série do ensino médio ter que cursar $2^{\underline{a}}$ série novamente. Enfatizaram que se sentiam desprestigiados com seus esforços, após terem realizado todas as demandas dos professores durante o primeiro ano da pandemia e que ficaram com a sensação de que os alunos, que não se esforçaram ano passado ou que abandonaram os estudos por qualquer motivo, foram 
atendidos em suas necessidades e eles não foram. A preocupação com a baixa qualidade do ensino, para a preparação para o ENEM, também foi mencionada.

\subsection{IQuestionário}

No terceiro encontro, entregamos os questionários a cada jovem participante e nos mantivemos afastados do local de entrega, mas próximos o suficiente caso tivessem alguma dúvida sobre os itens. Os questionários respondidos foram colocados dentro de um envelope por cada participante, sem necessidade de identificação. Posteriormente, buscamos o envelope e os jovens deram início aos estudos. As respostas do questionário descreveram a opinião de cada jovem participante referente à prática do grupo de estudos. A fim de apresentarmos um mapeamento da visão geral destas respostas, os 14 itens foram organizados em categorias, de acordo com a maior frequência recebida. Segue a sinterização das respostas após a Tabela 2 abaixo:

TABELA 2 - Categorização das Respostas

\begin{tabular}{|c|c|}
\hline CATEGORIZAÇÃO & FREQUÊENCIA \\
\hline Reforço da aprendizagem & Todos concordaram \\
\hline Fundamental para aprendizagem & $\begin{array}{l}\text { Dois jovens concordam } \\
\text { Um jovem discordou }\end{array}$ \\
\hline Motivação para os estudos & $\begin{array}{l}\text { Dois jovens concordam } \\
\text { Um jovem às vezes }\end{array}$ \\
\hline Animados com contato com colegas & Todos concordam \\
\hline Não consegue ir em frente & $\begin{array}{l}\text { Um jovem discorda } \\
\text { Dois jovens às vezes }\end{array}$ \\
\hline Organização para compreensão da atividade & $\begin{array}{l}\text { Dois jovens concordam } \\
\text { Um jovem às vezes }\end{array}$ \\
\hline Conteúdo da $3^{\mathrm{a}}$ série estímulo para $2^{\mathrm{a}}$ série & $\begin{array}{l}\text { Dois jovens concordaram } \\
\text { Um jovem às vezes }\end{array}$ \\
\hline Sobrecarga com a participação & $\begin{array}{l}\text { Um jovem discordou } \\
\text { Dois jovens às vezes }\end{array}$ \\
\hline Encontros aos sábados & $\begin{array}{l}\text { Dois jovens concordaram } \\
\text { Um jovem às vezes }\end{array}$ \\
\hline Dúvidas estudadas e compreensão & Todos concordaram \\
\hline
\end{tabular}




\begin{tabular}{|l|l|}
\hline & \\
\hline Planejamento no aplicativo & $\begin{array}{l}\text { Um jovem concordou } \\
\text { Um jovem às vezes } \\
\text { Um jovem discordou }\end{array}$ \\
\hline Tempo para encontros & $\begin{array}{l}\text { Dois jovens concordaram } \\
\text { Um jovem às vezes }\end{array}$ \\
\hline Organização para planejamento individual & $\begin{array}{l}\text { Um jovem concordou } \\
\text { Um jovem às vezes } \\
\text { Um jovem discordou }\end{array}$ \\
\hline Pandemia e disposição & $\begin{array}{l}\text { Um jovem discordou } \\
\text { Dois jovens às vezes }\end{array}$ \\
\hline
\end{tabular}

Fonte: autoria própria, 2021.

a) Observamos que todos os três jovens participantes concordaram que a atividade grupo de estudos serviu como reforço da aprendizagem, como motivador mediante contato com os colegas e auxiliou nas dúvidas e compreensão dos conteúdos;

b) A maioria, dois jovens, concordou que a atividade foi uma forma de organização e motivação para os estudos, Ainda, indicaram que os encontros aos sábados e o tempo pré-determinado entre 60-90 minutos foram favoráveis para o aprendizado, juntamente com o estudo do conteúdo da $3^{\underline{a}}$ série;

c) A maioria, dois jovens, sinalizou que às vezes, mesmo participando do grupo de estudos, não conseguia ir em frente nos estudos e que se sentia sobrecarregada. A situação da pandemia também interferiu às vezes na disposição para participar do grupo;

d) A minoria, um jovem, indicou que fazer parte da atividade grupo de estudos com os colegas não foi fundamental para seu aprendizado;

e) Os três jovens emitiram respostas difusas quanto ao planejamento para a implementação do grupo de estudos ter facilitado o acesso ao aplicativo Applique-se $e^{\circledR}$ ao estudo individual. Cada um sinalizou uma opção de resposta (concordo, às vezes e discordo).

\subsection{Parada emergencial contra a covid-19}

No dia 27 de março, sábado, o grupo de estudo se reuniria para o quarto encontro referente à revisão do conteúdo curricular da $2^{2}$ série, visto que de ${ }^{\mathrm{o}}$ a 16 de abril a unidade escolar agendou a I a avaliação da aprendizagem. Alguns professores avisaram que aplicariam avaliação da $2^{2}$ série nesse período.

Dos três jovens participantes, apenas um sinalizou que participaria desse quarto encontro. Os outros dois alegaram impossibilidade de participar por questões pessoais. Vale destacar que este encontro foi a primeira vez que a maioria sinalizou impedimento para 
comparecer. $\mathrm{O}$ fato de o conteúdo ser de revisão da $2^{\underline{a}}$ série, adicionado às novas medidas restritivas contra o coronavirus, pode ter desmotivado e afetado o interesse deles.

Infelizmente, nessa mesma quinzena de abril, a pandemia registrou números dinâmicos alterados, evidenciando ser a maior pandemia dos últimos cem anos em todo território nacional. No final de abril, o Brasil bateu seu próprio recorde do número de óbitos mensal nesta pandemia, chegando quase a 8I mil no final do mês (O GLOBO, 2021; WHO, 202I). Nova paralisação foi estipulada em diversas regiões do país, incluindo no estado do Rio de Janeiro. $\mathrm{O}$ município de Maricá decidiu prorrogar as medidas de restrição à circulação de pessoas (RIO DE JANEIRO, 2021b). Com isso, os encontros presenciais da atividade grupo de estudos foram interrompidos. Como o panorama da pandemia não apresentava perspectivas de melhoras em curto prazo, o grupo decidiu cancelar o estudo.

\section{Panorama geral dos resultados}

$\mathrm{O}$ acesso gratuito a conteúdos digitais em ambiente virtual de aprendizagem, adicionado as orientações do Conselho Nacional de Educação (BRASIL, 2020) e da Secretaria de Educação do Rio de Janeiro (RIO DE JANEIRO, 202Ia) foram vitais para se dar continuidade ao ensino, para as reflexões iniciais e para o desenvolvimento da investigação da prática metodológica da atividade grupo de estudos aqui descritos. O grupo concluiu o Io bimestre do conteúdo programático da $3^{\underline{a}}$ série no mês de março. Infelizmente, o período da implementação da atividade, que seria de março a junho de 2021, não pode ser concluído por cumprimento às medidas restritivas do município contra o coronavirus.

O Calendário de Estudos do grupo foi elaborado seguindo as OEs da $3^{\underline{a}}$ série como apresentadas no Plano de Estudos para Alunos 2021. O conteúdo curricular da $2^{\text {a }}$ série, cursada em 2020, fez parte da rotina individual de cada jovem participante, por terem se dedicado a esta série, sem necessidade de repetição do conteúdo nos encontros do grupo. Todos conseguiram seguir a agenda de estudos do Calendário conforme proposto pela pesquisadora.

Foram realizados três encontros consecutivos no mês de março do ano corrente. Os encontros iniciaram com a nossa participação direta com os jovens participantes para a coleta de informações e auxílio na prática metodológica. As informações coletadas consistiram das anotações de campo provenientes da observação, dos relatos da entrevista em grupo face a face e das respostas do questionário. Posteriormente, o estudo foi iniciado com a participação ativa de todos e com a consulta ao aplicativo educacional Applique-se ${ }^{\circledast}$ em conjunto. Observamos a rápida adaptação e a possibilidade da superação dos jovens participantes durante o aprendizado dessa atividade, em circunstâncias excepcionais devido à pandemia da covid-ı́.

A criação do grupo de estudos viabilizou a aproximação presencial dos jovens, atendida às medidas de segurança sanitária, e os retirou do desânimo e procrastinação para estudar que se encontravam, proveniente da ausência do ambiente escolar. Todos os jovens participantes 
concordaram que a atividade grupo de estudos atuou como reforço da aprendizagem, como motivador mediante contato com os colegas e auxiliou nas dúvidas e melhoria da compreensão dos conteúdos. A maioria concordou que a atividade é uma forma de organização e motivação para os estudos. Afirmaram que os encontros aos sábados e o tempo pré-determinado entre 6o90 minutos foram favoráveis para o aprendizado, juntamente com o estudo do conteúdo da $3^{\mathrm{a}}$ série. A maioria sinalizou que às vezes, mesmo participando do grupo de estudos, não conseguia ir em frente e que sentia sobrecarregada. A situação da pandemia também interferiu na disposição do grupo para participar.

Foi possível notar outras implicações da pandemia no cotidiano dos jovens participantes, como a longa duração do fechamento das escolas. Um dos participantes destacou que não conseguia entender a abertura de vários estabelecimentos comerciais e de serviços, como academias e escolas particulares, enquanto as escolas públicas continuavam fechadas. Não compreendia também porque o sistema de combinação de aulas presenciais e remotas não era colocado em prática. Os outros jovens concordaram com estas colocações. Nós informamos que esta decisão foi para mitigar os efeitos da pandemia do novo coronavirus, haja vista que os profissionais da educação não fizeram parte do grupo prioritário para vacinação.

Os jovens também relataram que se sentiram bem nos encontros do grupo e que tiveram dificuldade em encontrar o material escrito no aplicativo educacional, por ser diferente da plataforma do Classroom ${ }^{\circledR}$ utilizado em 2020. De modo concomitante, os jovens se sentiam ignorados pela gestão escolar e desprestigiados em seus esforços para cursar a $2^{\underline{a}}$ série do ensino médio regular durante o ano passado, em plena chegada da pandemia, já que lhes foi imposto

rever este mesmo conteúdo no primeiro semestre deste ano. Este fato aumentava ainda mais a preocupação com a qualidade de ensino ofertada para a preparação do ENEM.

Os impasses políticos no campo da saúde no Brasil, mediante a pandemia da covid-ı, agravaram expressivamente a situação da educação em todo território nacional, principalmente no que tange a abertura das unidades escolares e a retomada das atividades. De modo evidente, a educação básica precisa ser o centro das atenções governamentais, com o intuito de ser incluída no rol das atividades essenciais de nosso país.

Essa experiência prática também proporcionou a elaboração de uma lista de elementos essenciais para o planejamento da atividade grupo de estudos para fins escolares e acadêmicos, a saber:

I.Participantes - a seleção dos participantes precisa levar em consideração a disposição e o interesse de cada pessoa em participar, ter o mesmo nível de conhecimento, ter o mesmo objetivo para os encontros e possuir o material necessário para os estudos. As normas de participação de cada membro no grupo devem ser elaboradas conjuntamente, considerando a escolha de um líder para sua administração; 
2. Modalidade presencial ou remota - o tipo de modalidade empregada para os encontros do grupo de estudo depende da disponibilidade dos participantes para locomoção, dos recursos tecnológicos e do contexto social do momento (como a observância das medidas sanitárias para o bem da coletividade);

3. Local - caso os participantes optem pela modalidade presencial, a viabilidade do local deve observar a distância e o tempo para locomoção dos participantes para os encontros, assim como a disponibilidade do local e o contexto social do momento. Estas questões não são incluídas caso a modalidade escolhida seja a remota, quando se deve atentar se cada participante dispõe de recursos tecnológicos para a participação;

4. Conteúdo do estudo - a distribuição do conteúdo deve atender ao currículo programático apresentado pela instituição de ensino e aprofundando em temas conforme necessidade do grupo;

5. Calendário de Estudos - o planejamento do Calendário deve atender a finalidade a que se propõe: reforço de conteúdo baseado em um calendário institucional oficial de aulas e/ou avaliações. Esta agenda deve distribuir o conteúdo a ser estudado discriminando data/ dia da semana, turno e quantidade de horas dedicadas para cada etapa dos encontros;

6. Encontros - todos os participantes devem seguir a lista de normas para participação de cada membro no grupo, incluindo a indicação de um líder que terá a função de definir, junto com o grupo, o local de encontro antecipadamente e relembrar os conteúdos a serem estudados e discriminados no Calendário de Estudos. Todos devem comparecer com as tarefas concluídas e dúvidas anotadas. 


\section{CONSIDERAÇÕES FINAIS}

Transformações significativas estão sendo realizadas nos contextos socioeconômicos no mundo devido à pandemia iniciada no final de 2019. Não poderia ser diferente no Brasil onde a crise sanitária estimulou a possibilidade do hibridismo com o ensino presencial e remoto em todos os níveis escolares (PASINI; CARVALHO de; ALMEIDA, 2020).

A necessidade de se pensar em formatos pedagógicos mais dinâmicos, e que envolvessem professores e alunos do ensino médio em âmbito regional do Rio de Janeiro, estimulou avanços tecnológicos importantes: melhorias expressivas no acesso à cultura digital e melhorias no atendimento diferenciado à camada da população de jovens com restrições de acesso a essa cultura. Ainda, entre estes últimos, aqueles que não possuíam ferramentas digitais ou conectividade, passaram a ser atendido com material impresso e mediação pedagógica presencial na própria unidade escolar.

O estudo propiciou uma oportunidade aos jovens participantes de conhecer e de participar de mais uma atividade de estudo. A maioria relatou que a oportunidade os estimulou a estudar mais e de uma forma disciplinada. Os participantes saíram da zona de conforto do processo de aprendizagem passivo e se lançaram no desenvolvimento da modalidade presencial do grupo de estudo. Essa experiência emancipatória foi possível devido ao interesse comum, a disponibilidade e dedicação para participar da pesquisa. Os saberes intercambiados no grupo possibilitaram o desenvolvimento crítico e reflexivo individual e coletivo dos conteúdos estudados e da vivência in loco da atividade.

Sob outra perspectiva, o Plano de Estudos para Alunos 202I (RIO DE JANEIRO, 202ia) foi percebido como impositivo pelos jovens participantes que se sentiram subjugados do processo pedagógico referente ao planejamento do ensino remoto a eles direcionado. Paulo Freire (1996) já denunciava que essas ações são provenientes de um modelo de educação bancária quando o conhecimento é introjetado pelo aprendiz de forma não-crítica, castrando a relação ação-reflexão do ato de aprender. No que tange a dica motivacional apresentada no Plano, faltou uma orientação mínima referente à aplicação da atividade grupo de estudos, devido ao excesso de racionalidade do contexto tecnológico que se encontra imersa e que não passou despercebida pelos participantes. Em que pesem os benefícios da tecnificação do ensino remoto, principalmente neste contexto histórico, lacunas cognoscíveis carecem de espaço no contexto educacional.

Com este estudo desenvolvido em nossa cultura e durante a pandemia da covid-ig, esperamos ter estimulado um novo saber através desta alternativa prática para a aprendizagem escolar e para a vida; ter colaborado com os problemas específicos do cotidiano escolar ou para 
outros contextos semelhantes, estimulando o conhecimento tácito de cada um, com o propósito de gerar novos significados, contribuindo para a vida real de professores e alunos através de um olhar heurístico, levando à generalização naturalística dos resultados apresentados. Já advertia Horton e Freire (1990): nós temos que ser inseridos num processo permanente de busca, pois sem isso, nós morreríamos em vida. Assim, com o resultado desta nossa experiência, esperamos ter contribuído para a práxis de estratégias ativas que propicia visão crítica no processo de ensino-aprendizagem.

\section{REFERÊNCIAS BIBLIOGRÁFICAS}

ANTICH, Andréia V.; FORSTER, Mari Margarete dos S. Formação continuada na modalidade de grupo de estudos: repercussões na prática docente. Seminário de Pesquisa de Educação da Região Sul. IX Anped Sul, 2012.

BRASIL. Ministério da Educação. Educação e Coronavírus. CNE aprova diretrizes para escolas durante a pandemia. Publicado em 28 de abril de 2020. Disponível em http://portal.mec.gov.br/ultimas-noticias/I2-acoes-programas-e-projetos-637152388/89051-cneaprova-diretrizes-para-escolas-durante-a-pandemia. Acessado em i7 de abril de 202I.

. Presidência da República. Lei no 9.394, de 20 de dezembro de 1996. Lei das Diretrizes e Bases da Educação. Estabelece as diretrizes e bases da educação nacional, 1996.

DEMO, Pedro. Introdução à metodologia da ciência. $2^{-\underline{a}}$ ed. $5^{\text {a }}$ tiragem. São Paulo: Atlas, I99I.

DEZIN, Norman K.; LINCOLN, Yvonna S. Handbook of qualitative research. [Manual de pesquisa qualitativa, tradução nossa]. California: Sage Publications, 1994.

FONTANA, Andrea; FREY, James H. Interviewing: the art of science. [Entrevista: a arte da ciência, tradução nossa]. In: DEZIN, Norman K.; LINCOLN, Yvonna S. Handbook of qualitative research. California: Sage Publications, 1994, p. 361-376.

FREIRE, Paulo. Pedagogia da autonomia: saberes necessários à prática educativa. São Paulo: Paz e Terra, 1996.

HORTON, Myles; FREIRE, Paulo. We make the Road by walking: conversations on education and social change. [Fazemos a estrada caminhando: conversas sobre educação e mudança social, tradução nossa]. Philadelphia: Temple University Press, 1990.

LIMA, H. A. de B.; MOTA NETO, I. B. da. Desafios encontrados pela docência no ensino remoto diante da pandemia: uma revisão bibliográfica. Revista Ibero-Americana de Humanidades, 
Ciências e Educação, 7(4), p. 15-28, 202I. Disponível em https://doi.org/ro.5189I/rease.v7i4.940. Acessado em 18 de maio de 202I.

O GLOBO. Abril é o mês mais mortal da pandemia da Covid-ı9 no Brasil. Publicado em 24 de abril de 202I. Disponível em https://oglobo.globo.com/sociedade/abril-o-mes-mais-mortal-dapandemia-da-covid-I9-no-brasil-249866ri. Acessado em 24 de abril de 2021.

OLIVEIRA, Sebastião Luís de; SIQUEIRA, Adriano Francisco; ROMAO, Estaner Claro. Aprendizagem Baseada em Projetos no Ensino Médio: estudo comparativo entre métodos de ensino. Bolema, Rio Claro, São Paulo, v. 34, n. 67, p. 764-785, 2020.

PASINI, Carlos G. D; CARVALHO, Élvio de; ALMEIDA, Lucy Hellen C. A educação híbrida em tempos de pandemia: algumas considerações. Edital Emergencial o6/2020. Rio Grande do Sul: Universidade Federal de Santa Maria, 2020.

RIO DE JANEIRO (Estado). Plano de estudo para alunos 202I. Secretaria de Educação do Rio de Janeiro - SEEDUC-RJ. Apostila, 202ra.

- Prefeitura de Maricá. Prefeitura prorroga bandeira Laranja até quintafeira (08/o4). Disponível em https://www.marica.rj.gov.br/2021/04/o2/prefeitura-prorrogabandeira-laranja-ate-quinta-feira-08-04/. Acessado em 02 de abril de 202rb.

SCHOENHERR, Neil. Discovering why study groups are more effective [Descobrindo por que grupos de estudo são mais eficazes, tradução nossa]. Publicado em i7 de julho de 2006. Disponível em https://source.wustl.edu/2006/o7/discovering-why-study-groups-are-moreeffective/. Acessado em 04 de março de 202I.

SCHOTKA, Roberta. Successful Study Strategies: studying in groups. [Estratégias de estudo de sucesso: estudando em grupos, tradução nossa]. Boletim. Editado em 20 de novembro de 2020. Pforzheimer Learning and Teaching Center. Wellesley College. Wellesley, Massachusetts, Estado Unidos da América. Disponível em https://www.wellesley.edu/sites/default/files/assets/departments/pltc/files/students/Succ essful\%20Study\%20Strategies-\%20Study\%20Groups.pdf. Acessado em o2 de abril de 202I.

SILVA, Guilherme Henrique G. da. Contribuições de um grupo de estudos na formação inicial de professores de matemática. Práxis Educacional. Vitória da Conquista. V. 7, n. Io, p. 69-84, jan/jun, 2011. Disponível em https://periodicos2.uesb.br/index.php/praxis/article/view/651/539. Acessado em og de março de 202I. 
SIMONETTI, Vera M. M. Professores dos Estados Unidos da América: suas concepções teóricas e os auto-relatos de suas práticas docentes. In: 48 ${ }^{\underline{a}}$ Reunião Anual da SBPC, 1996, São Paulo. 48ª Reunião Anual da SBPC PUC-SP, v. 2, p. 24I, 1996.

SLAYMAKER, Kali. How to create an effective study group [Como criar um grupo de estudo eficaz, tradução nossa]. Última revisão em 20 de agosto de 2020. Disponível em https://www.collegeraptor.com/find-colleges/articles/tips-tools-advice/create-effectivestudy-group/. Acessado em 04 de março de 2021.

WORLD HEALTH ORGANIZATION. Brazil's situation [Situação no Brasil, tradução nossa]. Disponível em https://covid-I919.who.int/region/amro/country/br. Acessado em 02 de maio de 202I. 